\title{
Pota pu Fe Fam Akuxe Vit: Reza para Fazer a Mulher Ter o Filho Mais Rápido
}

Pota pu Fe Fam Akuxe Vit: Prays to make pregnancy faster

\author{
Maria Atilda Nunes \\ Universidade Federal do Amapá ${ }^{1}$ \\ Maria Zani Forte \\ Universidade Federal do Amapá ${ }^{2}$
}

Resumo. O objetivo deste trabalho é documentar e comentar os saberes tradicionais verbais (artes verbais) relacionados às formas de possíveis de fazer a mulher ter filho mais rapidamente do povo indígena Galibi-Marworno, os pota pu fe fam akuxe vit. Desenvolvemos uma reflexão sobre a forma e o significado desses textos que têm origem na oralidade. Para isso, utilizamos o instrumental básico de análise da forma de conhecimento do branco (epistemologia Ocidental), que já há muito tempo analisa o que considera 'textos' em sua forma e como essa se liga ao seu significado. A intenção é fazer este exercício com os textos analisados e, a partir disso, costurar a teia de significados sobre a forma de pensar indígena (filosofia indígena) que essa amostra de textos pode nos apresentar. Nesse sentido, entendemos as expressões de artes verbais indígenas como veículos do conhecimento tradicional e seu conhecimento pode nos explicar um pouco sobre a visão de mundo e filosofia do pensamento indígena.

Palavras-Chave: Galibi-Marworno. Pota. Línguas Indígenas do Amapá.

\begin{abstract}
The purpose of this article is to document and comment some traditional verbal knowledge (verbal arts) of the Galibi-Marworno indigenous people related to the possible ways to make women have children more quickly (pregnancy faster), the pota pu fe fam akuxe vit. For this, we develop a reflection on the form and meaning of these potas that has its use in oral format. To do this reflection, we use the basic instruments of text analysis from the Western Epistemology, particularly related to 'texts' in its form and how it is linked to its meaning. The aim of the same reflection is highlight meanings on the indigenous way of thinking (Indigenous Philosophy). In this sense, we understand the expressions of indigenous verbal arts as vehicles of traditional knowledge; his knowledge can explain about the worldview and the philosophy of indigenous thought, the Galibi-Marworno indigenous thought.
\end{abstract}

Keywords: Galibi-Marworno. Pota. Prays. Indigenous Language of Amapá.

\section{Introdução: informações gerais e algumas definições}

O objetivo deste trabalho é documentar e comentar os saberes tradicionais verbais (artes verbais) relacionados às formas de possíveis de fazer a mulher ter filho mais rapidamente do povo indígena Galibi-Marworno. Os Galibi-Marworno habitam a Terra Indígena Uaçá (doravante, TI Uaçá), na margem esquerda do rio Uaçá ao norte do Estado do Amapá. A maior aldeia é o Kumarumã com a população de (2.420) habitantes (DSEl, 2017). Há aldeias distribuídas à margem da BR-156, são bem pequenas: Aldeia Samaúma, Aldeia Tukay e Aldeia Anawerá. Também há a Aldeia Uahá no igarapé Juminã. Os Galibi-Marworno mantêm estreito contato entre os outros povos que habitam

\footnotetext{
${ }^{1}$ Graduanda da Licenciatura Intercultural Indígena, Universidade Federal do Amapá (Campus Binacional).

${ }^{2}$ Graduanda da Licenciatura Intercultural Indígena, Universidade Federal do Amapá (Campus Binacional).
} 
a mesma região, sendo eles: Palikur, Karipuna e Galibi Kalinã (GALLOIS; GRUPIONI, 2003). Atualmente a população Galibi-Marworno é de aproximadamente 2.553 pessoas (DSEI, 2017), falantes da língua Kheuól e língua Portuguesa.

Este estudo é uma pesquisa sobre os pota pu fe fam akuxe vit (trad. lit. 'reza ou assopro para fazer a mulher ter o filho mais rápido'), através de trabalho de campo na Aldeia Kumarumã (Terra Indígena Uaçá, Oiapoque, Amapá, Brasil, cf. mapa 1). Desenvolvemos uma reflexão sobre a forma e o significado desses textos que têm origem na oralidade. Para isso, utilizamos o instrumental básico de análise da forma de conhecimento do branco (epistemologia Ocidental), que já há muito tempo analisa o que considera 'textos' em sua forma e como essa se liga ao seu significado. A intenção é fazer este exercício com os textos analisados e, a partir disso, costurar a teia de significados sobre a forma de pensar indígena (filosofia indígena) que essa amostra de textos pode nos apresentar. Nesse sentido, entendemos as expressões de artes verbais indígenas como veículos do conhecimento tradicional. Sendo assim, seu conhecimento pode nos explicar um pouco sobre a visão de mundo e filosofia do pensamento indígena. Entendemos texto como uma expressão de arte verbal que associa alguma forma linguística a um significado. Os principais textos trabalhados neste texto são os pota, um tipo de 'texto' bastante comum na região do Uaçá.

Mapa 1: TI Uaçá, Oiapoque, Amapá, Brasil (GALLOIS; GRUPIONI, 2003)

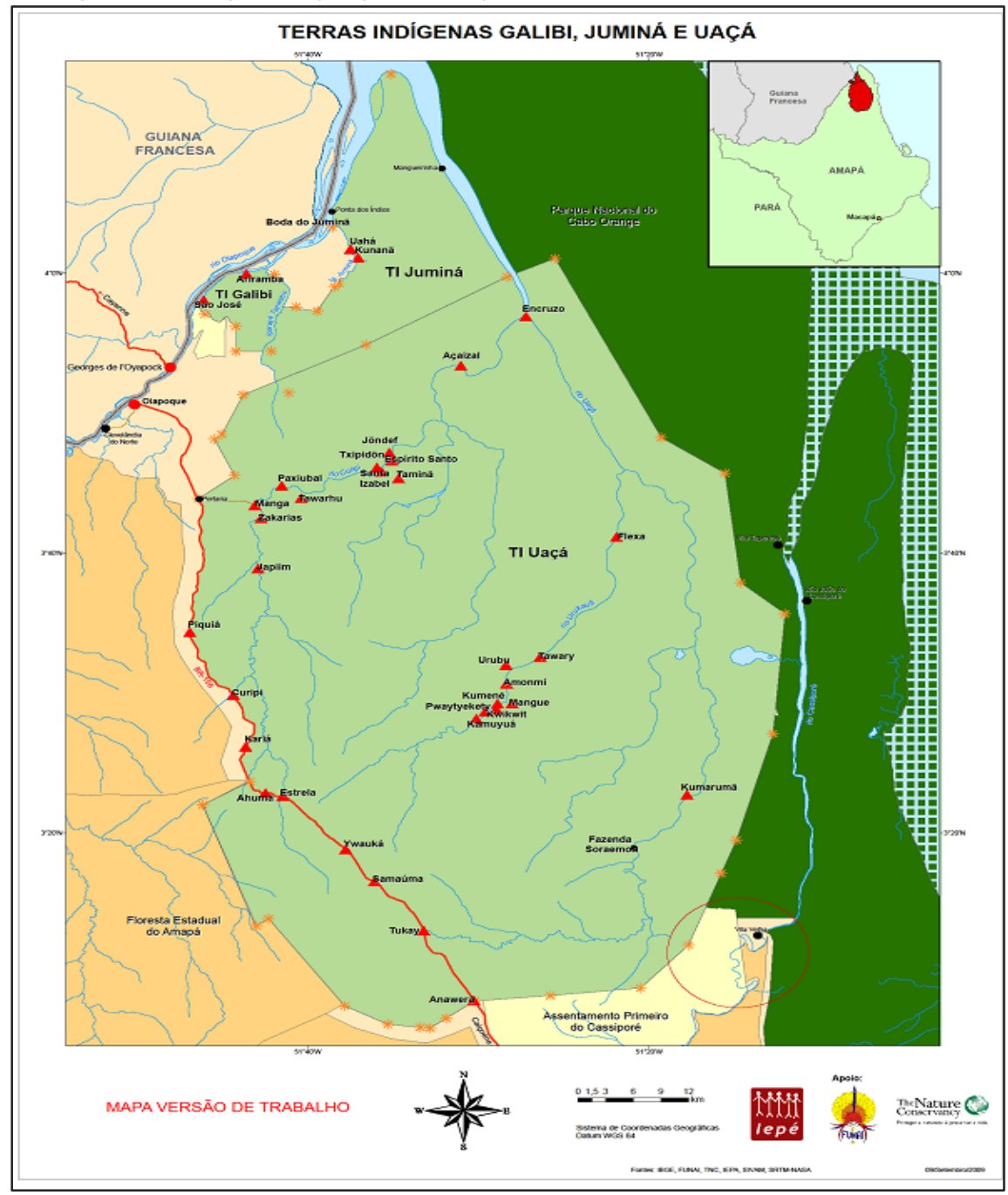


Potas são pequenos 'assopros' ou 'rezas' direcionadas a alguém em busca da prevenção ou da cura de um mal ou doença (RAMOS; SANTOS, 2016). Os potas são muito comuns nas práticas do discurso e nas artes verbais da região do Uaçá, compartilhadas com os povos Karipuna e Palikur, vizinhos de região. Atualmente, segundo a impressão das autoras deste artigo, nota-se um certo desuso dessas práticas discursivas por parte das mulheres mais jovens.

Os Galibi-Marworno constituem um povo de formação bastante distinta, com contribuição de povos de origem Arawak e Karib (GALLOIS; GRUPIONI, 2003). Atualmente, falam o Kheuól, língua crioula de base francesa, e o Português, língua franca da região. Os Karipuna e os Palikur, povos da região, também falam Kheuól, ainda que em graus distintos de domínio. Apesar de compartilharem a mesma língua, são povos de origens completamente distintas (CAMPETELA et alii, 2017; SILVA; SANTOS, 2019).

Como metodologia, entrevistamos algumas pessoas da aldeia que conhecem esses pota que servem para fazer parto de acordo com a cultura e tradição Galibi-Marworno. As pessoas que conhecem os pota são nossas verdadeiras 'fontes bibliográficas', o que nos fez colocá-las no centro de nossos esforços.

A opção pela entrevista aos conhecedores tradicionais favorece a discussão consciente sobre os símbolos e a metalinguagem/metonímia que envolvem os conhecimentos sobre os pota. Aqui, consideramos não só a metalinguagem (a linguagem sobre a linguagem) tradicional da academia, mas também a tradicional dos indígenas. Outros autores ou fontes de autores não-indígenas ocorrerão em nosso trabalho apenas de maneira a costurar e situar nossas ideias com as ideias que já circulam nos estudos acadêmicos sobre o assunto. Para isso, utilizamos um pouco da literatura já produzida por monografias de outros colegas desta Licenciatura Intercultural Indígena (RAMOS; SANTOS, 2016) e de autores que trabalharam em diversas áreas, como Linguística (CAMPETELA et alii, 2017; SILVA; SANTOS, 2019) e Antropologia (FRANCHETTO, 1986; GALLOIS; GRUPIONI, 2003; TASSINARI, 2003; VIDAL, 2001), bem como de fontes oficiais (FUNAI, ISA, IBGE, entre outras). Vale lembrar que os autores não-indígenas são apenas pano-de-fundo; aqui damos destaque às nossas fontes primárias, que são os sábios e anciões indígenas que entrevistamos.

O trabalho de descrição das artes verbais orais associadas a esses pota foi precedida pela descrição do próprio processo que envolve a execução desses potas. Esse pota é feito durante o parto da mulher, não é em qualquer momento em que ele é usado. Sempre acontece na casa da mulher que vai ter o bebê. No momento em que ela sente a dor de parto, se ela não pode ter o bebê rápido, aí que ela usa esse pota.

Somente algumas pessoas podem estar presentes lá com a mulher grávida dentro da casa no momento da dor de parto. Apenas familiares, como mãe, irmãs, sogra e parteiras, e no dia-a-dia de hoje as enfermeiras e técnicas de enfermagens acompanham. E outra parte da família, que são os homens, como pai, os irmãos, as crianças e o esposo da mulher com quem está tendo bebê e o ancião que está praticando esse pota, fica fora da casa.

A relação entre os diferentes corpos (entes) com o pota ocorre quando os anciões entoam o pota desses animais e eles vêm visitar a mulher que está tendo o bebê no mundo espiritual. Entre o visível e o invisível quem vê e ouve nesse caso é o ancião, o pajé que tem esse contato com os seres invisíveis no outro mundo (cf. VILHENA, 2018). Nessa pequena descrição, podemos ver que a 
relação de quem pode estar dentro da casa/próximo da mulher grávida e quem deve estar fora da casa/longe da mulher grávida é importante na distribuição das pessoas para a realização do pota.

Consideramos que o estudo sobre artes verbais orais deve levar em conta aspectos da performance, do padrão de interação, da saliência sociocultural, além, é lógico, dos aspectos da própria forma verbal em si. O padrão de interação básico envolve uma espécie de "assopro", em que se falam em voz bem baixa os potas em direção a certas partes do corpo da mulher, como o ombro, a barriga e o quadril. Outra parte importante da interação é a utilização de chás que fazem parte do tratamento, como os chás de alho, de manjericão, de pimenta do reino, tomados na água ou no mingau. Óleos de azeite de andiroba e banha de mucura são usados como remédio que auxiliam no esforço mecânico de puxar a barriga no momento do parto.

Esta pesquisa nos provocou uma reflexão sobre os pota e de seus usos, mas também abriu nossos olhos sobre as atitudes do nosso povo sobre esse gênero verbal do discurso composto por esses textos. Uma das justificativas para a preservação e estudo dessa manifestação de arte verbal oral do nosso povo é que os pota fazem parte do nosso patrimônio imaterial, da nossa cultura, tradição, crença e identidade (IPHAN, 2016).

Nós, como indígenas Galibi-Marworno, buscamos entrar no universo dos potas. Para isso, buscamos adotar certo distanciamento para ficarmos com o olhar mais atento, coisa que o nosso olhar do dia-a-dia não poderia nos proporcionar. As entrevistas com os conhecedores mais velhos nos fizeram perceber detalhes que nunca havíamos percebido antes. Percebemos que os pota não são somente cantos simples, mas um conhecimento organizado complexo. O seu uso e execução deve restringir-se somente a certas ocasiões necessárias, e respeitada toda uma série de significado e usos formais.

No parágrafo anterior, utilizamos o itálico para as palavras uso e forma, pois nos apoiaremos no recurso de tentar ligar forma ao significado e como um influencia o outro, conforme procedimento da dicotomia clássica Ocidental, que consiste na descrição da forma e da função do objeto de estudo. A convocação de um recurso dicotômico Ocidental não tem como objetivo ser uma amarra à tarefa de descrever esse gênero verbal do discurso, mas aparece apenas como um outro método para começarmos a expandir nosso conhecimento sobre o tema. Além disso, faz parte de nossa abordagem intercultural buscar descrever, com recursos científicos clássicos (dos brancos) somados a um olhar culturalmente específico e com conhecedores tradicionais do o gênero verbal oral descrito como pota, particularmente, aqueles relacionados a provocarem um bom parto.

Para isso, inicialmente, apresentamos o processo de entrevista e de tratamento dos dados. Nas seções seguintes, na análise dos textos selecionados, procedemos ao seguinte método (caminho). Primeiramente, apresentamos a tradução literal dos pota, ou seja, os seus significados palavra-por-palavra. Essa não é uma tarefa fácil, já que os pota podem ocorrer em diversas línguas distintas, com ênfase ao chamado Galibi Antigo, língua da família Karib, que possivelmente se refere a estágio anterior diacrônico (no tempo) do atual Kalinã (cf. BRETON et alii, 1999) ${ }^{3}$.

Em segundo lugar, buscamos fazer o que chamamos de tradução simbólica. Definimos tradução simbólica como o procedimento de análise em que buscamos ligar os elementos

\footnotetext{
${ }^{3}$ Apresentamos, no apêndice, um léxico, uma lista de traduções simples para o Português e para o Kheuól dos termos em Kalinã, conforme o entendimento dos anciões.
} 
simbólicos dos textos dos pota às suas formas e funções específicas de modo a extrair um nexo (ligação) entre essas duas partes. Buscamos, portanto, descrever a sua forma/estrutura versus a sua função/significado no contexto de uso linguístico desta prática discursiva organizada bastante comum na região do Uaçá.

Associado ao trabalho de fazer as traduções literais e simbólicas como análise inicial das formas e funções dos pota, também procedemos a entrevistas dos conhecedores e mestres deste conhecimento tradicional. A partir da interligação da análise das traduções e das perguntas e questionamentos levantados aos mestres conhecedores, fizemos alguns comentários sobre alguns aspectos que aparecem no universo dos potas. Os aspectos principais foram a ligação dos animais que aparecem nos potas e sua ligação com cada função exercida. Também observamos as reflexões dos velhos conhecedores sobre as atitudes das mulheres atuais em relação ao uso dos potas. A questão do desuso e falta de valorização atual é quase consenso.

Na parte que envolveu as entrevistas trabalhamos com quatro anciões e anciãs da Aldeia Kumarumã. O Senhor Raimundo Forte, de 66 anos, que aprendeu seu repertório de pota com a Dona Mariquinha, sua tia, nos apresentou o pota da Arraia; a Dona Maria Vitória Alexandre, 73 anos, conversou conosco sobre o pota do Poraquezinho; a Dona Estelita dos Santos, 55 anos, falou sobre o pota da Sucuri; por fim, o Senhor José Andrade Monteiro, 90 anos, compartilhou seu conhecimento sobre o pota da Pororoca. Todos são considerados como pessoas de notório saber em relação aos pota voltados para o parto. Ainda que também possa ser dominado por homens, o universo dos pota de parto é um conhecimento tradicional bem feminino. Muitos homens acabam aprendendo pota de parto para auxiliar suas esposas e familiares em situações difíceis.

Quanto à atitude atual das mulheres, podemos notar uma queda no interesse em aprendêlos e transmiti-los. Antigamente, as mulheres davam muito valor para esses pota, hoje as mulheres mais novas não dão o mesmo valor. Este trabalho, portanto, busca, em paralelo ao seu objetivo científico de contribuir para os estudos das artes verbais orais do discurso indígena e situá-los na arena mais ampla do debate acadêmico sobre o tema, também contribuir para um maior entendimento das artes verbais orais e de seus diversos gêneros como importantes para os processos de construção e preservação de identidade. Como consequência natural, também buscamos produzir material que possa servir de base para a transmissão e disseminação de conteúdo específico nas escolas indígenas da região, tão caras de materiais que cubram e discutam suas particularidades culturais. No limite, gostaríamos que este trabalho pudesse servir como material de base para os professores indígenas Galibi-Marworno prepararem suas aulas.

\section{Documentação e metodologia}

Nesta seção descrevemos de forma objetiva o processo de coleta, processamento e análise dos dados utilizados.

Entrevistamos quatro anciões da etnia Galibi-Marworno naturais da Aldeia Kumarumã conhecedores de alguns pota pu fe fam akuxe vit, são eles: 
Tabela 1: Anciãs e anciões da aldeia Kumarumã entrevistados

\begin{tabular}{|c|c|c|c|c|c|}
\hline Nome & Idade & Profissão & Pota & Duração & $\begin{array}{c}\text { Data da } \\
\text { entrevista }\end{array}$ \\
\hline Raimundo Forte & 66 & Servente da Escola & Ahe (Arraia) & $4 \mathrm{~m} 58$ & $09 / 09 / 2018$ \\
\hline Maria Vitória Alexandre & 73 & Parteira da Comunidade & Poraquezinho & $3 \mathrm{~m} 25$ & $27 / 09 / 2018$ \\
\hline Estelita dos Santos & 55 & Parteira da Comunidade & Sucuri & $5 \mathrm{~m} 43$ & $30 / 09 / 2018$ \\
\hline José Andrade Monteiro & 90 & Pajé da comunidade & Pororoca & $2 \mathrm{~m} 53$ & $18 / 10 / 2018$ \\
\hline
\end{tabular}

As entrevistas foram realizadas em Kheuól e gravadas em aparelho celular (modelo Galaxy J5 Prime), salvos em formato SD M4A. Transcrevemos apenas os pota. Sobre o conteúdo das entrevistas, apresentamos aqui apenas um resumo dos pontos mais importantes e das nossas anotações nos cadernos de campo.

Todos os pota depois de transcritos passaram pelo processo de tradução literal, onde buscávamos saber o significado de todas as palavras. Quando não sabíamos recorríamos aos anciões para que nos explicassem. Após esse primeiro passo, buscamos fazer uma tradução simbólica desses textos (chave de interpretação). Observávamos, geralmente, os principais personagens e sua ligação com a função de cura proposta pelo pota. Muitas vezes, o pota apresenta significados metafóricos que ligam e associam traços do personagem principal (por exemplo, o poraquê) à função de cura (parir rápido) como ferramentas para cumprir essa função (os choques do poraquê facilitam a dilatação do parto).

Abordamos tanto a forma dos pota, sua estrutura e performance, mas também seu conteúdo e função. Ao final, fazemos um comentário sobre as principais generalizações e conclusões que pudemos tirar deste trabalho.

\section{Traduções literais e simbólicas: definições}

Submetemos os quatro potas analisados a traduções do tipo literal e simbólica. Este passo inicial serve como método preliminar para compararmos todos os textos. As traduções do tipo literal, consistem em traduções palavra-por-palavra do texto. Os pota apresentam palavras em diversas línguas, sobretudo em Galibi Antigo. A ideia com a tradução literal é descobrir quem são os 'personagens' relevantes de cada um dos textos e que ações eles executam. Adiante, submetemos o texto a uma tradução simbólica, em que buscamos estabelecer uma ligação entre a função do pota aplicado a algum traço do 'personagem' relevante. Em geral, esse procedimento revela uma relação metafórica de transferência de alguma característica desse 'personagem' que possa vir a ajudar a resolver um mal específico da mulher grávida. Esse processo foi complementado com consultas posteriores aos anciões sobre dúvidas de interpretação.

O contexto do uso do pota (cenário) durante o parto da mulher. O pota (como evento) ocorre na casa da mulher que vai ter o bebê, no quarto, com um banquinho ao lado. Outras pessoas podem acompanhar internamente, sempre mulheres, como: mãe, irmãs, sogra e parteiras. Os homens ficam fora da casa, conversando e contado histórias, e somente são chamados em caso de necessidade. As figuras 1, 2 e 3, ilustradas por Milton Galibis, professor e artista visual indígena da Aldeia Kumarumã, dão uma ideia do cenário. 
Figura 1: Onde a mulher dá à luz (por Milton Galibis)

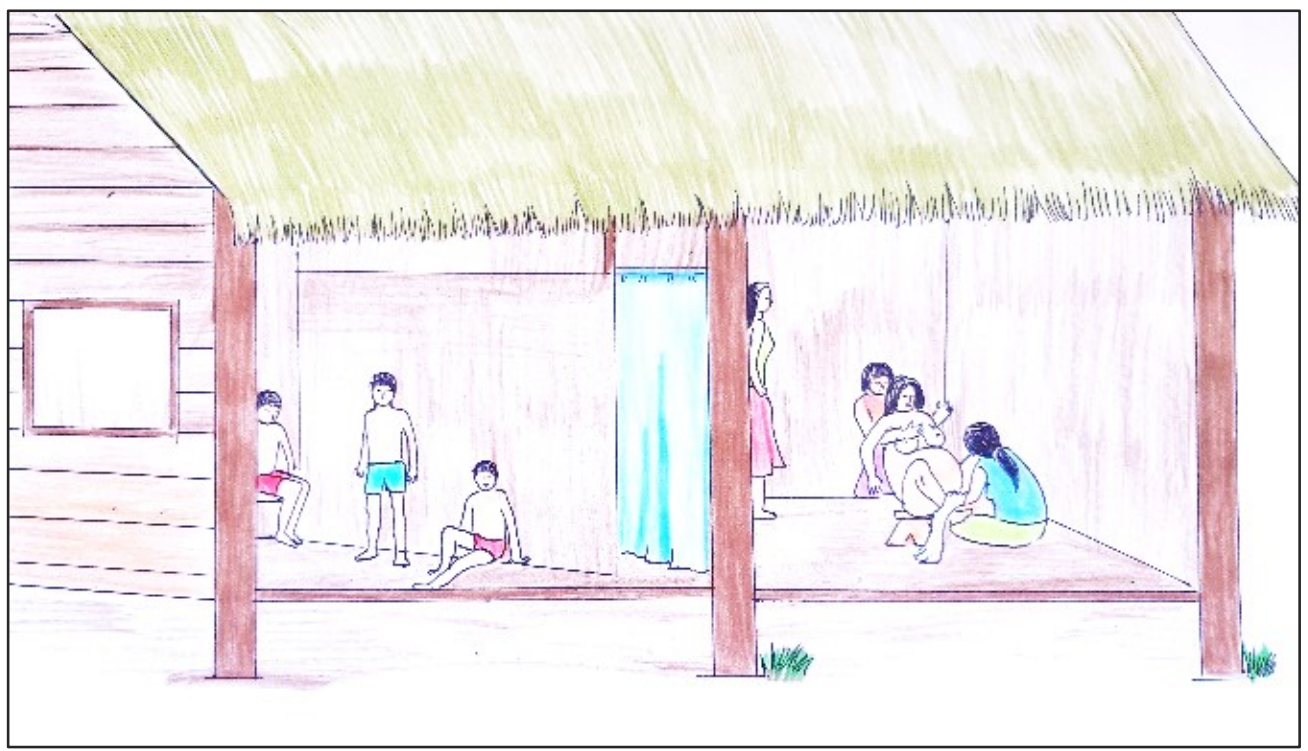

Figura 2: Mulher dando à luz e seus ajudantes (por Milton Galibis)

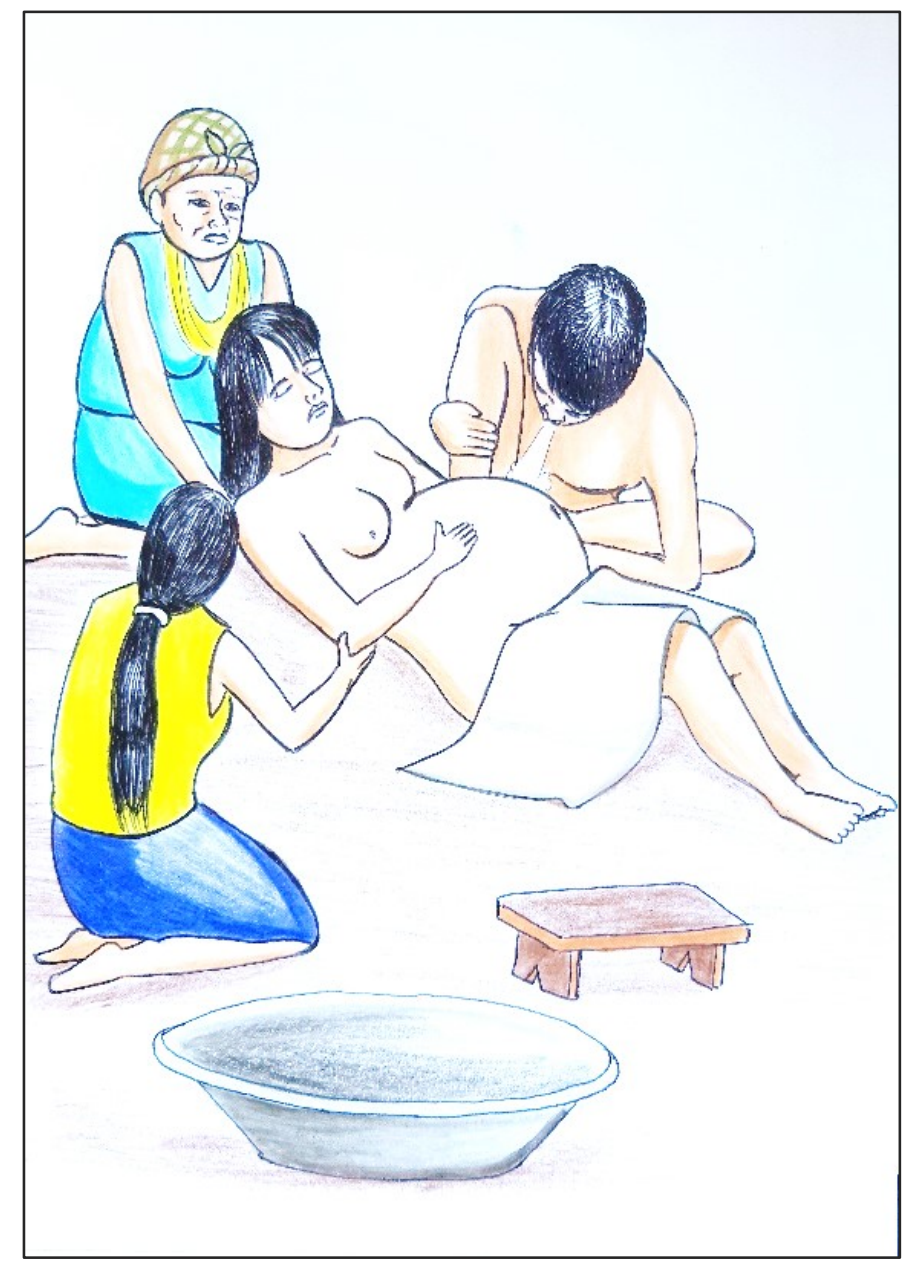


Figura 3: Banquinho auxiliar no parto (por Milton Galibis)

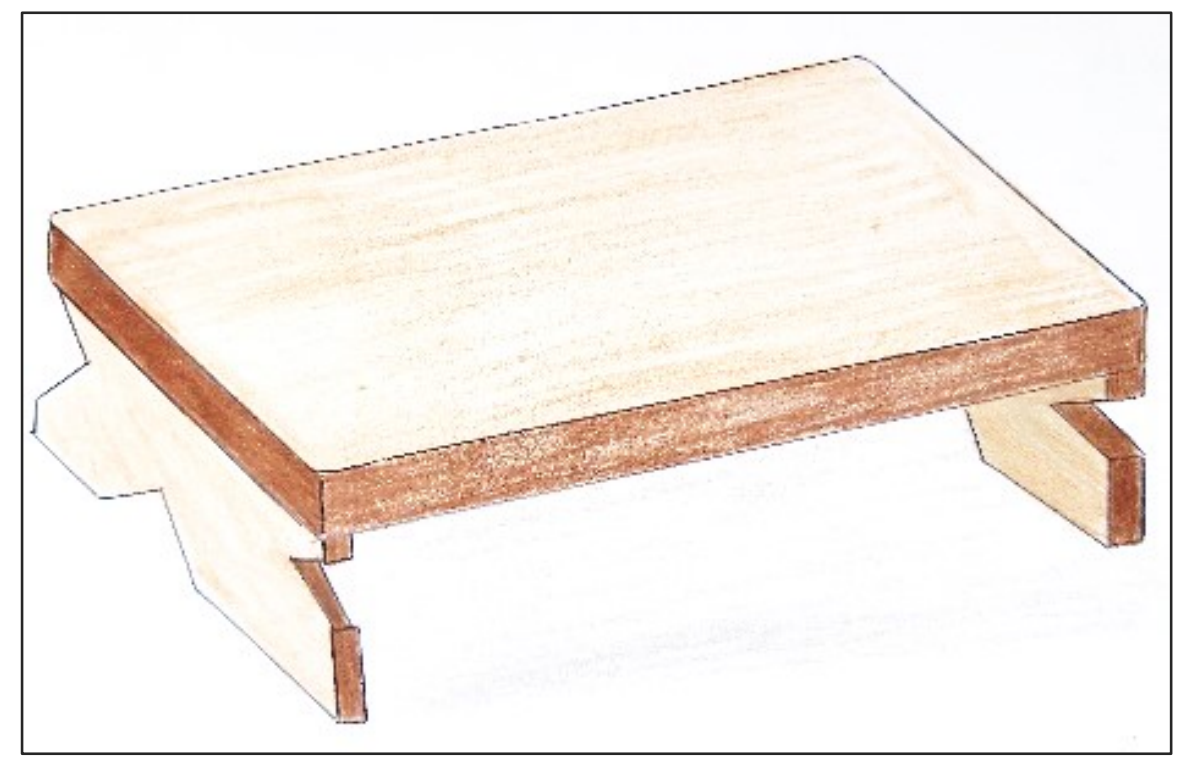

Transcrevemos os pota com uma estrutura de 'verso' e 'estrofe' com a intenção de associar a estrutura em que ele é recitado em voz baixa com as repetições, ritmo e pausas. Nas próximas seções analisamos um a um, conforme sua forma e seu conteúdo.

\subsection{Pota dji ahe (Potá da arraia, Senhor Raimundo Forte)}

Pota dji Ahe

murimuribu, murimuribu, murimuribu, tunã ie nãbu murimuribu arekenebo

\section{(Potá da Arraia)}

(arraia, arraia, arraia)

(água ie nãbu arraia barriga)

hixoxo ke no ynãte arukamã, arukamã tunã ie. (criança ke no ynãte, estrela-dalva, estrela-dalva água deles)

Este pota é assoprado tradicionalmente para que a mulher possa ter os filhos de maneira rápida e com pouco sofrimento. O formato do pota envolve apenas três pequenos versos assoprados com uma linha musical e repetidos algumas vezes. O trecho mistura palavras do Galibi Antigo (tunã, hixoxo) e alguns termos em Kheuól (ahe, ie, ke no).

A tradução literal, ainda que incompleta, nos revela que o personagem principal é a arraia (ahe). Outros elementos ocorrem como cenário, como a estrela-dalva e a própria água em si. Este pota foi ensinado ao Senhor Raimundo pela sua tia, Dona Mariquinha Trindade. Inicialmente, ele o aprendeu para ajudar a sua esposa, mas logo depois começou a ser procurado por muitas outras mulheres em busca de um parto rápido.

Kote $i$ ka hete ofõ lahivie kumã i ka maxe a li ka fonĩ tho vit ho pitxit-iela ofõ djilo.

(Senhor Raimundo Forte)

Como a arraia vive no fundo do rio, como ele anda lá dentro e como ela libera com rapidez muitos filhos. (tradução livre). 
O Senhor Raimundo nos explica em entrevista que a arraia é associada à facilidade em ter filhos, uma vez que ela é conhecida por ser um animal que libera seus filhos com muita facilidade e consegue se locomover rapidamente no fundo do rio. A presença da água está ligada à noção de 'fluidez' a que um bom parto está associado.

\subsection{Pota dji txiãgi (Potá do Poraquezinho, Senhora Maria Vitória Alexandre)}

\section{Potá dji Txiãgi}

ykolo, ykonã, ypoto, ynaynãgi, ynaynãgi,

tororo, arime, tororo, arime, tãgi, tãgi.

\section{(Pota do Poraquezinho)}

(ykolo, ykonã, ypoto, ynaynporaquê, ynaynporaquê,)

(tororo, arime, tororo, arime, poraquezinho, poraquezinho.)

Entrevistamos também a parteira dona Maria Vitória Alexandre de 73 anos, GalibiMarworno, moradora da aldeia Kumarumã, e ela nos explicou sobre o pota do poraquezinho. 0 poraquê nunca cresce, vive no mangue, e também dá choques. Os 'choques' servem para dar força para a mulher que está de parto, para aumentar as suas contrações de dor para ganhar o bebê com rapidez.

Segundo ela, disse que aprendeu esse pota com sua madrinha, uma anciã chamada dona Elvira, uma parteira antiga que fez muito parto. Dona Vitória queria mesmo aprender e queria ser parteira, então ela acompanhava a madrinha dela como ajudante nos partos, que ela havia feito durante essa caminhada. E ela aprendeu algumas coisas, contou também que começou a praticar o trabalho desde sua mocidade, aprendeu o jeito de puxar a barriga de uma mulher grávida, como preparar um chá e 'soprar' na pessoa. A Dona Elvira, sua mestra, era uma parteira sábia nessa parte de fazer o parto mais rápido usando os pota.

Txiãgi a un pwasõ elethik, a un animal ki ka thãgle , a puha ie ka sufle lasu ãgi pu fam-la akuxe biẽ vit i ka thãgle tximun-la ãdjidã ho mamã ho van. (Dona Maria Vitória Alexandre)

Poraquezinho é um peixe elétrico, um animal que dá choque, é por isso que tem o assopro do poraquê para a mulher ter um parto bem rápido, dizendo ela, o poraquê dá choque na criança dentro do ventre de sua mãe. (tradução livre).

O pota tem muitas palavras em Galibi Antigo que ainda não foram identificadas. A palavra para poraquê, no entanto, está em Kheuól, mas em uma espécie de registro próprio, onde a palavra é pronunciada 'reduzida' txiãgi>tãgi. A ideia central do pota é de 'articulação correta' ou de 'força mecânica', ou de 'jeito', representada pela facilitação dos 'choques' do poraquê.

\subsection{Pota dji kulev (Potá da sucuri, Senhora Estelita do Santos)}

Pota dji Kulév

Dumãgito, dumãgito, ynawera, eu sou, eu sou do matapi ynawera o...

Eu sou do matapi ynawera...

Dumãgito, dumãgito ynawera...

Eu sou, eu sou do matapi ynawera o...

Eu sou do matapi ynawera.
(Pota da Sucuri)

(Preso, preso, ynawera,)

(eu sou, eu sou do cacuri ynawera o...)

Eu sou do cacuri ynawera...

(Preso, preso, ynawera,)

(Eu sou, eu sou do cacuri ynawera o...)

(Eu sou do cacuri ynawera.) 
Entrevistamos a parteira Estelita dos Santos de 55 anos, Galibi-Marworno, moradora da Aldeia Kumarumã, recentemente passou a morar na aldeia Flamã. Trabalha de parteira há muito tempo. Falamos com ela sobre o pota para a mulher ter um parto rápido ela contou o da cobra sucuri. A sucuri é um animal que prende qualquer coisa e tem muita força, assim fortalece a dor na mulher. A Dona Estelita falou que aprendeu esse pota com a mãe dela, a dona Elvira, e ela quis aprender esse pota para ajudar as mulheres no parto. Ela aprendeu durante os partos que a mãe dela fazia, pois sempre a acompanhava em seu trabalho. A Dona Estelita quis também ser parteira, portanto, esse pota a ajudava no trabalho. Segundo ela, o pota de sucuri foi uma herança que a mãe dela deixou para ela.

Aphwe ki fam-la ke bwe há hemed-la, hete un bõ tã, fam-la ho van ke vini pi femal, a Kã kulévla ka sẽthe tximun-la, i ke bai un zés dji sutxi biẽ vit dji ho mamã ho van, osi mamã-la ka gãiẽ plezi dji fe fós pu tximun-la fét. (Dona Estelita dos Santos)

Depois que a mulher tomar o chá ou a água assoprada com o pota da sucuri, em alguns minutos as contrações da mulher aumentarão, de acordo com o pota da sucuri, a criança vai sendo empurrada pela sucuri, no momento das contrações a mulher sentirá mais vontade de fazer força para a criança nascer. (tradução livre)

O pota apresenta não somente Galibi Antigo, mas também português. A ideia central é a de 'força' nas contrações, representada pela sucuri.

\subsection{Pota dji pororok (Potá da pororoca, Senhor José Andrade)}

\section{Pota dji Pororók}

tunãweio parana aranã, parana aranã erero, mãbomãbo kiaro aranãranã erero aranãranã erero,

mirimiri txikanu aranãranã erero, mirimiri txikanũ̃ aranãranã erero.

\section{(Pota da Pororoca)}

(água-sol onda onda, onda, onda, onda erero,) (arraia em cima da lama kiaro onda-onda erero onda-onda erero) (esquilo, criança-menino erero,) (esquilo, criança-menino erero,)

Entrevistamos o senhor José Andrade Monteiro de 90 anos, morador e pajé da aldeia Kumarumã, perguntamos sobre o pota para uma mulher ganhar bebê com rapidez. Ele falou para nós do pota da pororoca. A pororoca é uma onda muito forte, assim serve para a mulher ganhar bebê com rapidez, através do empuxo forte. De acordo com a pesquisa ele falou que aprendeu esse pota com um indígena da etnia Waiãpi, o senhor Waiwai, também pajé.

Pororók a un lamẽ dji lamahe hót ki ka pote tut bagaj, akõhã i ka fe tximun-la vinĩ vit dji ho mamã ho van. (Senhor José Andrade Monteiro)

Pororoca é uma onda de maré alta que leva todas as coisas, assim também ela faz a criança movimentar no ventre da sua mãe e nascer rápido (tradução livre).

Este pota apresenta palavras em Galibi Antigo e Kheuól, muito embora tenha sido transmitida ao Senhor José por um indígena Waiãpi, Senhor Waiwai, uma etnia falante de uma 
língua Tupi-Guarani. Isso mostra que a sabedoria dos pajés ancestrais falantes de línguas Karib era muito dominante em toda a região há muito tempo. Esse pota tem como 'personagem' principal a 'onda' que tudo carrega, e tem como foco a força do bebê para nascer. Podemos definir a ideia central desse pota é a de 'empuxo do bebê', representado pelos solavancos das ondas da pororoca.

\section{Outros aspectos dos Pota dji Akuxe Vit}

Apresentamos quatro pota que têm como função acelerar o parto: o da Arraia, do Poraquê, da Sucuri e da Pororoca. Cada um deles foi traduzido de maneira literal e de maneira simbólica. Os 'personagens' centrais de cada um dos pota apresentam características consideradas boas e positivas de serem adquiridas pela mulher em trabalho de parto. A arraia está associada à 'fluidez'; o Poraquê, ao 'jeito correto'; a Sucuri, à 'força'; e a Pororoca, ao 'empuxo do bebê'. Essas quatro vantagens são evocadas através da execução correta dos pota.

A forma de transmissão e uso dos pota envolve a utilização de outros instrumentos, para além da própria voz. Os pota podem ser assoprados nos chás oferecidos às grávidas (pimenta-doreino, alho, manjericão etc.), mas também na água, nos óleos utilizados para puxar a barriga, ou diretamente direcionado a certas partes do corpo da mulher, como ombro, barriga e quadris.

O executor do pota repete várias vezes o mesmo canto. Há três formas principais: em voz alta, em assovio, ou em pensamento. As duas últimas são utilizadas em contextos onde não se deseja ensinar o pota aos presentes. A primeira opção é utilizada quando o orador se sente à vontade para repassar esse conhecimento aos presentes.

É importante notar que a utilização dos pota não é de qualquer jeito. Ou seja, há casos em que esses potas não podem ser utilizados. Uma restrição refere-se a bebês que não estão na posição correta na barriga (sentados ou atravessados). Nesse caso, esses quatro potas não são indicados.

Atualmente, a atitude das mulheres indígenas não é muito positiva em relação ao uso exclusivo dos pota e do parto na aldeia. Após várias mortes por problemas de parto, muitas têm buscado ter seus filhos no hospital. A utilização dos pota está associada a um contexto em que as mulheres têm filhos em casa, com a queda no número de mulheres que recorrem a parteiras tradicionais, a demanda por conhecedores diminuiu bastante nos últimos anos.

A forma de transmissão continua sendo o da participação. Se não estão ocorrendo muitos partos nas aldeias, não há mais tanta transmissão desse gênero verbal que serve de remédio. As meninas de hoje não estão tendo a oportunidade de verem suas mães, avós, ou mesmo seus pais, recorrerem aos tradicionais pota.

É interessante perceber que os pota muitas vezes misturam línguas diferentes. A língua que mais aparece é o Galibi Antigo, mas também encontramos palavras em Kheuól, Português, em Palikur e Waiãpi. Essa mistura nos mostra que muitos povos diferentes foram influenciados pelos mesmos discursos tradicionais compartilhados. Especificamente, os povos Karib devem ter tido os pajés mais fortes da região, daí o uso do Galibi Antigo. No entanto, é importante notar que há também o uso de outras línguas, o que mostra que os outros povos também contribuíram com algumas inovações nesse gênero de arte verbal. 
Ainda que o uso dos pota tenha se reduzido muito por causa das mudanças sociais e políticas que o povo Galibi-Marworno vem passando, muitas mulheres jovens estão buscando resgatar o conhecimento sobre essas tradições. Nesse sentido, já há um movimento nas aldeias que visa à revitalização e valorização dessas práticas (CAMPETELA et alii, 2017).

\section{Considerações finais}

A escolha por esse tema passa pelo nosso desejo de valorizar nossos traços que formam a nossa identidade indígena Galibi-Marworno. Os pota são nosso patrimônio imaterial e, por isso, devem ser estudados, preservados e conhecidos. Os pota não são exclusivos dos Galibi-Marworno, mas também são conhecidos por nossos parentes mais próximos, como os Karipuna e os Palikur. Assim, estudar os pota não só ajuda a tentar entender as características do povo Galibi-Marworno, mas também de todos os povos da TI Uaçá.

Fizemos esse trabalho com muito entusiasmo. Tivemos a oportunidade de conhecermos mais a fundo os sábios idosos, José de Andrade, Estelita dos Santos, Raimundo Forte e Maria Vitória dos Santos. Isso nos provocou uma reflexão sobre o que já não transmitimos mais aos mais jovens, por causa das mudanças que nos cercam e estão cada vez mais velozes. Uma dificuldade grande que tivemos decorreu do fato de muitos desses idosos serem evangélicos, o que lhes impedia, de certa forma, falar dessas práticas tradicionais.

Por causa dessas intensas pressões de setores religiosos que entraram nas aldeias indígenas, muito de nossa cultura tradicional está deixando de ser transmitido. Este trabalho, portanto, reúne uma série de materiais que podem servir para pesquisas comparativas sobre o tema (Linguística, Antropologia ou outras áreas), e assim difundi-lo. Também podemos dizer que este trabalho teve como objetivo servir de base para trabalhos a serem desenvolvidos nas escolas indígenas, em prol da Educação Escolar Indígena específica e diferenciada (conforme Constituição Federal de 1988), e também para uma abordagem da cultura indígena com foco no universo da mulher indígena, como em publicações voltadas também à área da saúde e às profissionais da saúde não-indígenas, para que conheçam o nosso contexto de mulher indígena.

\section{Referências orais}

Estelita dos Santos. 2018 - Pota da Sucuri - Aldeia Flamã

José Andrade Monteiro. 2018 - Pota da Pororoca - Aldeia Kumarumã

Maria Vitória Alexandre. 2018 - Pota do Poraquezinho - Aldeia Kumarumã

Raimundo Forte. Setembro-2018; Pota da Arraia, Aldeia Kumarumã.

\section{Referências}

BRETON, R.; PAISA, M. B.; BERNABÉ, J. Dictionnaire Caraïbe-Français. Paris: KARTHALA Editions, 1999 [1665]. Disonível em < https://horizon.documentation.ird.fr/exl-doc/pleins_textes/pleins_textes_7/b_fdi_03_02/ 010017260.pdf> Acesso em 14 nov. 2018.

DSEI. Caracterização do DSEl Amapá e Norte do Pará, conforme Edital de Chamada Pública n; 2/2017 (item 3.1.). Manuscrito, 2017. Disponível em < https://portalarquivos2.saude.gov.br/images/pdf/2017/agosto/28/ Caracterizacao-DSEI-Amapa-Chamada-Publica-n-02-2017.pdf>. Acesso em 14 nov. 2018. 
CAMPETELA, C.; SANTOS, G.; SILVA, E.; SILVA, G. Documentação linguística, pesquisa e ensino: revitalização no contexto indígena do norte do Amapá. Revista Linguíftica, v. 1, n. 13, 2017, p. 151-167.

EDITORA SARAIVA. Saraiva Jovem: Dicionário de Lingua Portuguesa. São Paulo: Saraiva, 2012.

FRANCHETTO, B. Falar Kuikúro. Estudo etnolinguístico de um grupo karíbe do Alto Xingu. Volume II. 1986. Tese (Doutorado em Atropologia Social), Museu Nacional, Universidade Federal do Rio de Janeiro, Rio de Janeiro, 1986.

GALLOIS, D. T.; GRUPIONI, D. F. Povos indígenas no Amapá e Norte do Pará: quem são, onde estão, quantos são, como vivem e o que pensam? São Paulo: lepé, 2003.

IPHAN. Guia de pesquisa e documentação para o INDL: patrimônio cultural e diversidade linguística. Brasília: IPHAN, 2016.

RAMOS, L. O.; SANTOS, K. A Marca Pataje Kasab da Aldeia Manga. Monografia. Licenciatura Intercultural Indígena, Universidade Federal do Amapá, 2016.

SILVA, G. R.; SANTOS, G. M. F. O Kheuól do Uaçá: Perspectivas em Pesquisa In OLIVERIA, E. S.; VASCONCELOS, E. A.; SANCHES, R. D. (Orgs.). Estudos Linguísticos na Amazônia. Campinas/SP: Pontes, 2019.

TASSINARI, A. M. I. No bom da festa: o processo de construção cultural das famílias Karipuna do Amapá. São Paulo: EdUSP, 2003.

VIDAL, L. Mito, história e cosmologia: as diferentes versões da guerra dos Palikur contra os Galibi entre os povos indígenas da Bacia do Uaçá, Oiapoque, Amapá. Revista de Antropologia, v. 44, n. 1, 2001; p. 117-147.

VILHENA, Erdeson dos Santos. A Língua dos Karuãna. Revista Brasileira de Línguas Indígenas, vol. 1, n. 2, pp. 37-50, 2018. 


\section{Apêndice.}

Glossário trilíngue Galibi Antigo-Kheuól-Português

Definimos glossário como uma lista de palavras, geralmente em ordem alfabética, que dá o significado das palavras que são explicadas e traduzidas para outro idioma (EDITORA SARAIVA, 2012). São essas palavras que estão citadas embaixo que ocorrem nos textos utilizados neste artigo.

Arekenebo (GalibiAtigo): Van (Língua Kheuól); parte de um corpo humano, barriga.

Arukamã (GalibiAtigo): Gho zetwél (Língua Kheuól); uma estrela que chamamos de estrela-d’alva.

Dumãgito (GalibiAtigo): Phwi (Língua Kheuól); o que é preso.

Hixoxo (GalibiAtigo): Tximun (Língua Kheuól); crianças.

Mãbomãbo (GalibiAtigo): Ahe lasu labu (Língua Kheuól); é um animal da água que anda encima da lama arraia encima da lama.

Mirimiri (GalibiAtigo): Lẽgelẽge (Língua Kheuól); pequeno animal mamífero de cauda peluda, que vive nas árvores, esquilo.

Murimuribu (GalibiAtigo): Ahe (Língua Kheuól); animal que vive no mar, arraia.

Parana (GalibiAtigo [?]): Lamẽ (Língua Kheuól); uma grande onda.

Txikanũ (GalibiAtigo): Tximun txiwom (Língua Kheuól); criança menino.

Tunã (GalibiAtigo): Djilo (Língua Kheuól); água.

Weio (GalibiAtigo): Solei (Língua Kheuól); sol. 